\title{
Work-life balance for native and migrant scholars in German academia: meanings and practices
}

\author{
Irina Gewinner \\ Institute of Education and Society, \\ University of Luxembourg, Luxembourg, Luxembourg and \\ Institute of Sociology, Leibniz Universität Hannover, Hannover, Germany
}

\begin{abstract}
Purpose - The purpose of this paper is to address notions and practices relating to work-life balance for native German scholars and researchers who have migrated from the former Soviet Union (FSU). Issues will be explored from a cultural perspective, identifying culturally based interpretations of work-life balance.

Design/methodology/approach - Foregrounded in a diversity approach, this empirical study draws upon explorative interviews to discuss work-life balance in German academia. To overcome monocultural observations, 25 German scholars and 11 researchers originating from the FSU were interviewed, all of whom are highly skilled female scholars.

Findings - Findings demonstrate that individuals with diverse cultural backgrounds can perceive huge differences in identical working conditions. The study links meanings of work-life balance with individual practices and identifies key components of work-life balance within this population. It also discusses the decisions that scholars make about starting families or remaining childless for the sake of their careers.

Originality/value - This study is the first of its kind in Germany, and represents a strong implication for policies and their evaluation. It identifies the crucial role played by culturally rooted notions relating to work-life balance practices.
\end{abstract}

Keywords Work-life balance, Culture-sensitive approach, German academia, Native and migrant scholars

Paper type Research paper

\section{Introduction}

German academia, as a workplace, has a twofold reputation. On the one hand, it stands for excellence, performance, innovation and knowledge production with a high global standing. This is especially pronounced in enrolment rates of incoming undergraduates, $\mathrm{PhD}$ students and scholars with migration backgrounds who seek to perform further research in German scientific institutions. Germany, currently, sits third after USA and UK when ranked in terms of attractiveness for foreign students (study.eu, 2018). On the other hand, German academia arouses strong criticism for insecure working conditions and precarious career paths for scholars. This uncertainty is usually traced back to structural organisation and recent changes, which have resulted in cumulated individual risks relating to securing work.

Competitive working conditions are representative of careering and quantifying the terms of power rather than resisting performance pressure (Clarke and Knights, 2015). This is especially true for Germany with its historically large proportion of junior, i.e. temporary, staff in contrast to a small number of senior scholars in tenured positions. Statistics disclose an increase of non-professorial faculty in the last decades against the background of much more slowly growing numbers of research institutions and unlimited contracts (Kreckel, 2016; Federal Statistical Office, 2016). Positions under professorial level represent varying

(C) Irina Gewinner. Published by Emerald Publishing Limited. This article is published under the Creative Commons Attribution (CC BY 4.0) licence. Anyone may reproduce, distribute, translate and create derivative works of this article (for both commercial \& non-commercial purposes), subject to full attribution to the original publication and authors. The full terms of this licence may be seen at http:// creativecommons.org/licences/by/4.0/legalcode

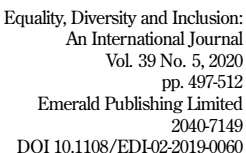


EDI

39,5

498

status groups, constituting a diverse body of junior scholars, such as graduates, $\mathrm{PhD}$ students, researchers with a doctorate and senior researchers pursuing a second $\mathrm{PhD}$, called Habilitation. Statistically, only one-fourth of junior scholars might achieve a tenured position (Möller, 2011a, b), commonly professor or, in fewer cases, lecturer or research manager. Career-related concerns are illustrative of flexible work and its individualisation, which inevitably forces scholars to advance their academic life courses in order to secure rare tenured positions and associated high social status within the system. This requires much effort, time, expenses, networking competence and, not least, a close match to the cultural ideal of the "real scholar", an ever-available male without family obligations, clearly devoted to research. Time resources for external activities shrink, which represents a substantial challenge for family and care obligations.

Past research has indicated a gendered discourse of work-life balance in academia globally, but especially so in the German context (Toffoletti and Starr, 2016; Dorenkamp and Süß, 2017; Tzanakou, 2017; Sieverding et al., 2018). It found that female scholars are disproportionally exposed to challenges associated with research and teaching, aiming at securing a tenured position, and tensions in private life pertinent to caregiving as mothers have to work more and often irregular hours (Powell, 2015; Dubois-Shaik and Fusulier, 2017). While studies usually put dominant groups of people at the centre of attention, mostly native women with children, far less is known about the work-life balance of other groups represented in German academia, how they understand work-life balance and realise family formation under precarious working conditions. This is crucial to capture a comprehensive notion of work-life balance and its realisation with regard to temporary contracts, diversity and family friendliness of academic institutions.

Against this background, a question arises, namely, the nature of work-life balance of various groups in the German academic system, especially for childless individuals and immigrants, the latter representing a clear minority within this landscape. In other words, how do native Germans and scholars with migration backgrounds cope with the ever-growing pressures, requirements and expectations of performance and scientific output on the one hand, and family life on the other hand? These issues are important, since little is known about the link between notions and practices developed by the advantaged and also people who are deemed disadvantaged in host country contexts but who simultaneously possess advanced qualifications and high social status. This is particularly true for highly skilled female migrants from the former Soviet Union (FSU) to Germany. So far, little research has considered the diversity of cultures among scholars in Germany, thus leaving it unclear, whether or not this social group is representative of a homogeneity of values associated with work-life balance.

To address these issues, this study seeks to highlight key concerns pertinent to understanding the reconciliation of work and family life. Although work-life balance for white educated women has been tackled in previous literature, the following will use a cultural perspective in order to provide a fresh view on diversity and the effects of intersectionality that accompany gender equality in academia. Specifically, the paper focusses on individual viewpoints and work-life balance patterns of female scholars stemming from different academic contexts and, thus, coined by divergent cultural values. Such an approach makes it possible to disclose individual demands that are increasingly associated with career progression, spatial mobility and core biographical events as well as demonstrate the interpretation of the value of work-life balance in ostensibly similar social groups.

Based on a qualitative empirical study, the paper focusses on native German and migrant Russian-speaking researchers in German universities in order to reveal their comparative perceptions of work-life balance. Highly qualified scholars from the FSU represent one of the largest migrant populations in German academia (Wolffram, 2015; $\mathrm{DAAD}, 2016$ ), with a high proportion of women in various subjects ranging from STEM to 
humanities. The standardisation of qualification sequences in German academia is comparable to that used in the FSU, which facilitates familiarisation following immigration. Thus, the paper contributes to current discussions on work-life balance, exemplifying

German academia.

\section{Theoretical considerations}

Aspects of work-life balance have been elaborated by a considerable number of studies. These not only particularised specific factors aiming at reducing work-family conflict, such as kindergarten care provision or flexible working hours, but also discussed ways to further promote work-life balance on the meso or national level. However, their common denominator discloses a number of top-down policies - either offered by the state or single organisation - thus revealing several problematic issues. First, all initiatives contain mostly conventional actions, such as part-time work, paid parental leave, day-care provision, job sharing or flexible work (Smith and Gardner, 2007). These formalised policies, varying by employer, are subject to interpersonal negotiation and are rarely incorporated into national or regional mandatory policy. The degree of work-life balance thus correlates with the employer's commitment to employees' life satisfaction in a broad sense and is less dependent on individual expectations, values and readiness to claim reconciliation of work and private life.

Second, most studies consider majority, often middle-class, populations and often exclude subjectivities lived by minor groups, such as immigrants in host societies. The European Commission describes vulnerable social groups as those that experience a higher risk of poverty and social exclusion than the general population (European Commission, 2016). Patterns of work-life balance for ethnic minorities, migrants and other disadvantaged populations have been less studied and thus the knowledge generated from these insights risks bias. Skilled migrants from the FSU have not yet formed the centre of scientific attention, therefore, information about their work-life balance in a German competitive segment of the labour market is very limited.

In order to disentangle understandings of work-life balance from the cultural perspective, three main aspects can be considered in detail and compared between native and migrants: first, subjective perception of work, its necessity and role in personal life, expressed in temporary contracts and chances for career advancement in academia, for these can play a decisive role in family formation and subsequent work-life balance. Second, family formation practices or predisposition to such among scholars, since, according to the Federal Statistical Office, female non-professors and professors are more often involuntarily childless, as compared to their male counterparts or women with university degrees working in other sectors (Federal Statistical Office, 2016). Third, notions of and actual patterns of reconciliation of work and family life, since these can shed light on the value of work-life balance in the majority population and migrant scholars in German academia.

\section{The role of work in academia}

Work crises as a result of technological progress and erosion of standard employment relationships in academia not only urge top individual performance, but also entail a rethinking of work-life balance. Ongoing contemporary discussions mostly address the type of contract (with temporary considered disadvantageous) and focus on individual practices to overcome precariousness, pressure and uncertain career trajectories (Gill, 2010; Busso and Rivetti, 2014; Arrigoitia et al., 2015). The male standard employment relationship, i.e. the stable full-time contract common in the 1980s, appears as a normative standard, implicitly rendering job security a culturally rooted general value orientation. Thus, the absence of a tenured contract may be regarded as personal failure and inability to succeed in academia. Such circumstances might be especially challenging for women in double career 
relationships, forcing them to communicate the value of their work and finding a balance between an academic career and family.

For the German scholars who represent a majority population, the literature addresses tense working and career advancement conditions of researchers at German universities (Jacob, 2014). Closely related to this are financial aspects (especially in the postdoc phase, women are more likely to have part-time jobs than their full-time male counterparts) and insecure positioning in the community. Further studies point to a strong sense of parental responsibility among scholars (Meyer, 2006), which mirrors a reduction of working hours after starting a family, especially for women (Gewinner, 2017). Furthermore, a high conflict potential between work and family is often attributed to the German scientific culture (Beaufaÿs, 2013) that can be characterised through conservative, male-dominated norms (Krell et al., 2006). Work-life balance thus has a relatively high value in the German native population, which results in patterns of prioritisation of career goals and potential postponement of other life events.

Against the background of persisting feudalism (Ullrich, 2016; Van Dyk and Reitz, 2016) and academic capitalism, the two main features highlighting precariousness in German research institutions, the official discourse celebrates meritocracy and individual excellence (Salminen-Karlsson et al., 2018). Junior scholars are largely exposed to favouritism and the reputation power of their mentors and deploy diverse strategies to gain access to influential academic networks (Dorenkamp and Süß, 2017; Gewinner, 2018). Given the pervasive cultural ideal of a productive male scholar, women are often negatively stereotyped and seek to dissociate themselves from attributes that do not comply with this cultural ideal, sometimes incorporating postponement or even renouncement of family formation.

Literature on work-life balance of highly skilled in Germany is far less consistent and detailed, regardless of the considerable research on gender and migration. Because highly skilled migration has long been regarded as privileged, information on reconciliation of academic work and family-related decisions of this social group is lacking. Scant findings point to intersected strands of diversity in migrants' careers and gender inequalities faced by female scholars from Eastern Europe pursuing further careers (Wolffram, 2015). Past research describes careers of migrant women as compromised or even failed, especially if they migrate as dependants (Sang et al., 2013; Vohlídalová, 2014).

\section{Family formation in academia}

Disaggregating researchers from other highly qualified population groups gives an insightful picture. For instance, data from the German Federal Statistical Office (2016) demonstrate that young scholars in Germany are more likely to be childless than other highly educated workers in other sectors. Especially within the scientific community, family postponement or late catching-up can be identified among women after they reach the age of 35 or significantly later (Metz-Göckel et al., 2014).

The issue of family formation runs simultaneously with the stage of professional establishment in a scientific community and is especially pertinent to junior researchers. Many individuals feel themselves forced to choose between work and family due to perceived difficult working and qualifying conditions at universities. Risks are often associated with uncertain career advancement processes due to the paucity of resources, limited career opportunities and the excellence imperative. In addition to the gender culture, Germany also holds clear ideas as to the order in which professional and family life events are to be mastered. For example, the idea of professional consolidation followed only afterwards by transition to parenthood is common (Bernardi and Keim, 2013). So far, no scientific results are available to relate how far this sequential perspective prevails among scholars. However, if it were also applicable to this social group, then precarious careers in the German academic system would also hinder family formation, and could lead to postponement or even renouncement of family. 
While structural arguments and policy criticism largely dominate the discussion of family formation for German junior researchers, cultural influences on childlessness within academia are not well researched. Past research has documented that egalitarian dual-career role models mutate into traditional gender roles as soon as scholars have their first child (Gassmann, 2018). At the same time, the "natural" persistence of the male breadwinner model (PfauEffinger, 2004; Rusconi and Solga, 2011) is primarily attributed to welfare state policy and structural obstacles rather than to dominant cultural values in individuals. Yet, continuing to work alongside parenting is well connected to a negative archetype of a bad mother who neglects her children because of work. Studies showed that German female scholars greatly reduce their working hours to care for children (Gassmann, 2018; Beham et al., 2019).

Current research argues that people with migration experience possess cultural norms and values which differ significantly from the German experience (Milewski, 2010; Krapf and Wolf, 2016; Gewinner, 2017). Findings demonstrate that migration decisions are often met by highly qualified women driven by career-oriented motivation (Bosch and Ramos, 2013). This applies in particular to female migrants from the FSU: their family values, dominant in Russian-speaking countries, can be described as double-breadwinner models (Haas et al., 2004). Gewinner (2017) found that Russian-speaking first-generation migrant scholars bring their cultural traditions to Germany and are more likely to run families alongside academic work, which is unusual for the German majority of academics, especially for women. At the same time, generational interdependency is rather high (Hilevych, 2016). This implies a synchronicity of several spheres of life, which includes employment and family formation ("working motherhood") as well as support of mothers by extended networks within the family.

\section{Reconciliation of academic work and private life}

Another related issue concerns the reconciliation of care and working obligations. Flexibility in combining work and care responsibilities is representative of gender equality, diversity and equal opportunities in the workplace. Recent studies consider this to be poorly represented in German academia, which is assumed to be increasingly responsible for dropouts from academia (Briedis et al., 2014; Schürmann and Sembritzki, 2017). At the same time, policy targets predominantly women, which implies that work-life balance remains almost exclusively a female issue. Men, although increasingly put under pressure between academic work and family obligations (Oechsle and Reimer, 2016), are rarely addressed in mentoring and supporting opportunities as caregivers (Leinfellner and Bomert, 2017).

Past research made temporary contracts responsible for the postponement of family formation in academia because they do not allow long-term planning for either men or women (Möller, 2011a, b; Beaufä̈s, 2013; Konsortium Bundesbericht Wissenschaftlicher Nachwuchs, 2017). Additionally, the interplay of structural and cultural factors has a negative effect on mothers, yet research hardly discussed their aftermath on childless scholars. Largely represented conservative norms favour men, especially if they have children, because they comply with the breadwinning and responsible gender role (Krell et al., 2006). Coupled with the uncertainty caused by temporary employment contracts and shaky job prospects, this traditionalism either supports a dropout from academia or promotes childlessness among scientific workers, particularly women (Metz-Göckel et al., 2014; Kunadt, 2015).

\section{Data and methods}

\section{Data collection}

The link between culturally rooted meanings of work-life balance, its practices and perceptions in German academia can be best addressed using a comparative approach. Various aspects and factors that mirror individual career constructions interacting with family formation or already existing family obligations can thereby be illuminated. Given the novelty of the target groups and the desideratum to extensively illuminate the 
EDI

39,5

502

components of their work-life balance, this study draws upon an explorative comparative interpretative approach and focusses on German and migrant researchers from the FSU.

In order to answer the research questions, primary data were gained from semistructured explorative interviews with German native and Russian-speaking migrant female scholars. German interview partners were selected based on their affiliation with social sciences and the humanities, since the proportion of women is highest in these fields of study. After an internet screening of all German universities, participants were invited using a written form. The researcher tried to ensure that interviewees pursuing a doctorate were equally distributed both at research assistant positions and in structured $\mathrm{PhD}$ programmes, a new form of doctorate in Germany that aims at reducing the arbitrariness of mentors and dependency of junior researchers on internal power structures. About 40 per cent of 74 approached persons agreed to give a telephone interview.

The target sampling technique was used to identify Russian-speaking scholars. The researcher accessed the field deploying a snowball technique or onomastics procedure, the latter based on an online search for most common Russian names. Due to field constraints, migrant scholars from all possible disciplines were considered for a telephone interview and approached in written form. Utilised interview guides helped achieve comparability of results pertinent to the general themes, such as employment situation, work satisfaction, career prospects, family situation and organisation of private life. Additionally, interview protocols helped retain essential notes featuring each interview.

Every interview lasted about $60 \mathrm{~min}$, and all participants consented to the audio recording of interviews and use of data for subsequent analysis. Conversations with German-speaking scholars occurred in German, with Russian-speaking researchers in Russian to fully capture the important notions and meanings, their hierarchy as well as common practices. At the end of each interview, respondents were given the opportunity to address interview-related topics and provide thoughts and perceptions of their paths within academia. This strategy accomplished the issues activated in prior conversations and provided extra valuable information beyond the guided interviews. The names of all respondents have been changed for the sake of anonymity and ethical reasons.

After the interviews, the data were transcribed and put into MaxQDA. Analysis drew on the grounded theory approach and coding paradigm developed by Glaser and Strauss (1967), Corbin and Strauss (2008). This method allows conceptualisation of the object of investigation and the building of categories based on participants' own interpretations. The codes therefore provide direct access to individual perceptions, order the meanings and roles these play in personal lives, and dimension the degree of importance and their respective realisation in individual daily practice. After identifying the categories, causal relationships between single social phenomena were established, accompanied by description of contextual conditions and revealing the reasons for and consequences of the resulting human agency strategies. This builds the construct of work-life balance in German and Russian-speaking scholars, and enables comparison. One coder coded the data twice: after the first round, the data were re-coded after four months in order to safeguard the results.

\section{Sample description}

Table I provides an overview of employment status and fields of study in German- and Russian-speaking study participants. To draw a comprehensive picture, this investigation considered scholars at different career stages, since work conditions and associated contextual factors might influence the notion of work-life balance and individual practices of its realisation. Although German male scholars were also interviewed, their views have been omitted within this study for the sake of comparability of results pertinent to women.

The age of German respondents ranged from 28 to 45 . About half were single at the time of the interview, the other half in a stable partnership, and only a minority were married. 
Only 11 scholars in the sample had children: 8 had one child, 1 had two children and 2 had three children each. Respondents were dispersed throughout the German academic landscape, most had moved from other locations, a feature foregrounding German academic mobility as a whole. All interviewees had temporary contracts and were inclined to further pursue scientific careers, yet with varying degree of tenacity.

Russian-speaking study participants came deliberately to Germany either to obtain a doctorate or to advance their careers. Most originated from major Russian cities, disproportionally represented by St Petersburg and to a lesser extent Moscow, only two participants from Ukraine and one from Moldova. All respondents were independent migrants under the banner of education or employment migration; only one, well educated, respondent had accompanied her German husband to Eastern Germany, but this occurred shortly before the fall of socialism, and therefore, migration policy restrictions at that time meant that she could migrate without undergoing an exhausting document proof procedure. Except for one professor, all respondents had temporary contracts. Contrary to their German counterparts, 10 Russian-speaking migrant scholars were either married (7) or in stable partnerships (3), only one being single. Six women were childless, three had one child and the other two each had two children.

\section{Results and discussion}

\section{The value of work and work environment}

Both German- and Russian-speaking participants were passionate about their jobs, yet the value of work had a somewhat different meaning for the groups. While all scholars from the FSU moved to Germany in order to continue their academic careers, either to obtain a doctorate or to pursue research, their German counterparts often already possessed resources essential for a successful academic career path. This was expressed through the means that Russian-speaking scholars needed to activate while searching for a job, approaching a potential mentor and relocating to Germany, which points not only at high selectivity of migrant individuals with a contract at a German academic institution, but also at possible career delays:

Oksana (Postdoc, RU (Russia): I didn't see myself in a Russian system, I wanted something else, like German. I've seen various systems, in Hungary, the US, Germany [...] I went for Germany because the competitive pressure in not so high as compared to the US.

Anna ( $\mathrm{PhD}$ student, Ukraine (UA): I studied biology in Ukraine and obtained my master's degree in Germany. I wanted to proceed to a further level and strove for a scholarship to finance my $\mathrm{PhD}$. Once I thought of returning to Kiev, but honestly - the financial and equipment situation is unacceptable there. Science is not financed, and I worked in the best lab in Ukraine! It just takes too long to conduct a trial or specific analysis there because they do not have proper up-to-date equipment or money to buy it.

\begin{tabular}{llcc}
\hline Category & Differentiation & German & Russian speaking \\
\hline \multirow{2}{*}{ Gender } & Female & 25 & 11 \\
Employment situation & (Assistant) Professor & 1 & 3 \\
& Postdoc/Researcher & 6 & 4 \\
& Project/Research assistant without PhD & 8 & 2 \\
& Graduate school PhD student & 7 & 1 \\
& Scholarship & 3 & 1 \\
Original fields of study & Arts + Humanities & 1 & - \\
& Social sciences & 10 & 1 \\
& STEM + Medicine & 15 & 4 \\
& & - & 6
\end{tabular}

Work-life balance

Table I.

Overview of the profession-related characteristics of interviewees 
EDI 39,5

In contrast, German researchers often reported a "smooth transition" from studies at master's level or a previous work engagement, often arranged by a scientific supervisor or mentor. Even when they initially lacked network resources, they possessed the cultural capital and language proficiency required for the organisation of financial support and work routine:

Julia (Postdoc, DE): I had some good contacts. My current boss, the principal investigator of the project I'm involved in, knew my mentor. My mentor told me about a vacancy there, and apparently, I was recommended.

Melanie (PhD student, DE): I received a PhD scholarship for four years, but I neither had an office at the university, nor direct colleagues. I missed that a lot, so I built my network myself. I took additional lecturer contracts just to be close to the academic environment.

Similar employment conditions in terms of temporary contracts made it possible to compare respondents' attitudes towards academic work and its place in the hierarchy of professional and personal success and related work-life balance. Social background appeared to play a crucial role: while all Russian-speaking migrant participants originated from families of academics, known as intelligentsia, their German counterparts came from middle-class families in which either nobody or only one parent had higher education. Given the social status of academic work in Germany, working as a scholar represented a great deal of personal success, social recognition and respect especially for German women. Russian-speaking migrants considered this work as a normative, individual achievement, but as a perfectly natural one. Coupled with the post-socialist legacy of the regularity of women's employment, migrant scholars were less critical of the potential termination of their contracts. More importantly, although they considered temporary work as suboptimal, it was seen as inevitable to gain experience and cumulate network density, which implied their readiness to change affiliations if necessary. One Russian-speaking scholar reported that her contract had been prolonged for half a year four times in a row. However, most of the migrant women had stayed at one institution for a substantial period of time.

Although migrant researchers possessed an advantage over their German colleagues in the form of certain academic habitus, they voiced scepticism about their obtaining the rank of professor, having a migration background in Germany, a circumstance that highlights that internationalisation and inclusiveness in German higher education are better addressed at the undergraduate level. Although the higher echelons of academic hierarchy are officially open for all suitably qualified, they are at the same time subtly closed to those who are less familiar with the German context. This is consistent with findings on the social background and cultural habitus of the German professoriate (Möller, 2011a, b) that revealed that the latter largely incorporates individuals socialised within a culture of strong academic attainment.

With this in mind, susceptibility to favouritism and sympathy of supervisors holds a crucial role over the notion of individual excellence, which has a huge implication for work-life balance. While Russian-speaking scholars with lack of professional contacts needed the counterbalance of hard work, German academics who were well-equipped with established network resources enjoyed joint projects and protection from their supervisors. This significantly facilitated a good reputation in the scientific community and their own positioning in the institution, which diminished some performance pressure:

Maria (Postdoc, DE): I once tried to make enquiries about publishing a book based on my $\mathrm{PhD}$, but a publishing house representative showed little motivation to advise me. He figured out the name of my supervisor accidentally, and suddenly completely changed [...] This name immediately opened the door for me and effectuated even more in some contexts. 
Larissa (Postdoc, UA): Ooooh yes, I enjoy unlimited trust from my supervisor. Of course, people with sharp tongues interpret this as if I had a kind of sexual attraction or whatever. They just want to think so because I'm a woman, I wear a skirt and I have a leading position. They don't believe I could have achieved seniority through hard work.

Native Germans, although acknowledging the prestige of their professional activities, reported on a lack of work-life balance and the omnipresence of work in their lives. This implied not only the dominance of hard work, but also a poor life planning potential due to temporary employment contracts. Pursuing research meant putting all their eggs in one basket, postponing other activities and life course events that might distract from achieving a permanent position. Obtaining tenure appeared to be the priority goal, especially to those who originated from non-academic families, as the investment made into previous steps were considered particularly high. Not achieving tenure would suggest personal failure and crisis especially for German scholars.

\section{The value of partnerships and children}

Almost half of Russian-speaking respondents had children at the time of this study, which points to the post-socialist legacy and the idea of motherhood as crucial for every woman regardless of educational level. For their German counterparts, the picture was similar, yet the role of social background was apparent again: except for three women, all mothers were educational climbers. The traditional notion of a family was essential for these respondents, and realisation of this social normative greatly constituted their understanding of life fulfilment and related work-life balance.

The ways in which Russian-speaking and German women communicated having children and the role of their partners in caregiving is particularly noteworthy. Although migrant scholars were aware of professional uncertainty, they believed that mothering at a young age does not harm professional performance, since one is productive and active:

Judith ( $\mathrm{PhD}$ student, $\mathrm{RU})$ : Many German scholars have unrealistic visions in life. They study until they are 40 and plan a family simultaneously. This is not going to work! The younger one is, the easier it is to manage family and work simultaneously, I believe.

Moreover, migrant scholars considered marriage and childbirth crucial components of their lives and regarded potential unemployment as time they could devote to family. This implicitly indicates that they deem men breadwinners, who should be responsible for dependants in difficult times. This notion helped Russian-speaking women not to overstate the dramatic consequences of possible job loss or inability to secure their next academic position, as well as viewing family as a second route to success.

German scholars largely regarded themselves as responsible for caregiving and providing the best starting conditions for their children. They understood motherhood and fatherhood as autonomous activities where both parents have intense roles and do not regard children as career obstacles. Instead, they expressed the opinion that prior to children, they had believed that it would be necessary to decide between child(ren) or career, which turned out not to be the case due to support from partners, relatives or public facilities:

Ute (Postdoc, DE): You know, I learnt to manage my time better, honestly. Previously, I thought I can do that, but only after the birth of my children I realised that I can be more productive, more target-oriented, more efficient than I was earlier.

Strikingly, German mothers deliberately distributed care obligations in order to overcome traditional gender role patterns and hardly regarded their partners as a source of income in case of potential unemployment. Practices associated with the realisation of work-life balance ranged from shared parental leave to leave performed predominantly by a partner,

Work-life balance 
and shared caregiving. These German women reported that their careers were prioritised due to expected benefits, and men were taking care of their children. Simultaneous parenthood and academic career implied high demands on men and their overall acceptance of gender equality norms:

Julia (Postdoc, DE): I have a son from my first husband, and my current partner supports me a lot. He cares for my child, since my profession has priority at the moment. He used to work overtime but has significantly reduced it now.

Jessica ( $\mathrm{PhD}$ student, $\mathrm{DE})$ : My husband took the whole parental leave and spent a year with our child. He acknowledges my professional development and my workload.

Lora ( $\mathrm{PhD}$ student, $\mathrm{DE})$ : After giving birth to my child, I started working three months later. My partner does not have a university degree, so he supports me emotionally and has no problem taking parental leave. I'm going to earn more later on.

For Russian-speaking mothers, simultaneous parenthood and academic careers were accurately related to a post-socialist tradition, yet with adjustment to situational conditions. Being alone in a host country and lacking habitual support from older generations, migrant women greatly relied on egalitarian partners and state childcare facilities:

Larissa (Postdoc, UA): We have two children [...] My husband and I never argued about the division of tasks at home. He is in charge of all parental obligations in the morning - waking up children, making breakfast, taking them to kindergarten and school. He cooks dinner daily. I take care of children in the evening - we play together and I read my younger son a book before bed [...] My husband has the same occupation as me but in another institution, so we understand each other's needs and requirements.

Inga (full professor, RU): My husband and I never discussed division of household responsibilities. It just happened: when I dust, he hoovers, when he does laundry, I iron, when he mows the lawn, I take care of flowers, and so forth. Being double career partners means saving time and spending it with children. Planning is everything [...] I always tell my $\mathrm{PhD}$ students to send children to bed early to allow work in the evening.

As these experiences show, being a double career family with a like-minded partner significantly facilitates women's work-life balance and career success. Both women are married to European men and perceive conservative values as obstructive to career advancement, especially for women. This is striking, since all Russian-speaking mothers were liaised with German (or Western European) men.

\section{The value of institutional support}

German discourse regularly addresses institutional frame conditions as responsible for risky career paths and lack of work-life balance in scholars. Interestingly, German researchers indeed believed that policy should launch further measures at meso and macro levels to guarantee secure work settings for those without tenure. They suggested introducing more permanent positions, structuring teamwork to counteract individualisation and creating projectable employment conditions for achieving a work-life balance. They largely assumed that organisational frameworks were subject to further change. However, interviews revealed the extent of unconscious bias on the individual level, as respondents reported on occasional discriminatory ways they were treated at work, for instance, stereotypes associated with children's sickness, negative comments regarding reduced working hours or criticism of scientific performance:

Ute (Postdoc, DE): It upsets me to see colleagues being suspicious about that or even asking twice whether I really managed to reach a deadline as if I were sick $[\ldots]$ 
Tanja (Postdoc, DE): During my PhD, I received a scholarship but fell pregnant. So I consulted the family service at university to determine the options available for further employment and childcare. Do you know what they told me? These aunts there said "You shouldn't worry about anything, you can still opt for Hartz IV! [German long-term unemployment benefits - I.G.]”

As Tanja's experience shows, even university employees scheduled to assist with work-life balance and diversity issues are not always able to completely disengage themselves from persisting role ascriptions and gender stereotypes. Overbooked organisation-related kindergartens or the continued absence of such facilities at many German universities have reinforced public opinion regarding the necessity of private childcare. Cultural values coupled with negative stereotypes, resulting from deviance from this norm, produce institutional culture that diverges from the declared gender equality and diversity strategy.

Organisational or state support constituted a habitual resource for Russian-speaking scholars. Accustomed to using state kindergarten facilities, some mothers relied on the family service at universities, subordinated to the office for equal opportunities. Their experiences unveiled an unambiguous preservation of conservative norms in caregiving providers:

Isolda (Ass. professor, Moldova): There is a MiniCampus, where I leave my son about 15 times a year. The lady who organises it spreads rumours saying what a bad mother I am, constantly leaving my child for all day with strangers.

\section{Family formation and childlessness in German academia}

While the typical timeframe for family formation for Russian-speaking researchers was before during the $\mathrm{PhD}$, with exceptions for those unwilling or single, the German timeframe commonly fell after obtaining a doctorate or significantly later, symbolising the logical next step after completing a professional project. German respondents attributed childlessness and postponement of family formation to their workload:

Matilda (Postdoc, DE): I have so much to do to reach my next career stage. My partner is also a scholar. We live in different cities and spend weekends together. So why should I give birth to a child without knowing where I will be living next year? I would have to spend a lot of time with my child, and I just can't imagine it now, I have so much work and related plans.

Lena ( $\mathrm{PhD}$ student, $\mathrm{DE})$ : I need full concentration in work. I do a lot - and I work in social sciences where teams rarely work together and its nature is individualistic. After obtaining a tenured position I will probably think of children.

Carina (PhD student, $\mathrm{DE}$ ): I told my boyfriend's relatives that I get children only when I clearly see that he is going to share parenting responsibilities and reduce his work hours. Otherwise it won't work.

Matilda not only lacks certainty around planning, but also has idealised notions of parenting. She is convinced that children take up most of their parents' time and is not ready to sacrifice her job for that. Interestingly, idealisation of parenthood is common for childless scholars because they overlook alternative role models in academia. Again, this finding is consistent with recent research (Gewinner, 2017; Schürmann and Sembritzki, 2017) that identified that idealisation of parenthood is particularly detectable for German childless natives.

Native and migrant scholars showed different levels of willingness towards family formation, which might result from a different connotation and understanding of the role of parenting. While German researchers linked maturity with a stable contract, their Russian counterparts associated adulthood with having children. Indeed, the German cultural notion of maturity is deeply rooted in the establishment of self as an independent person, which is largely in line with tenure. This feature represented a culturally rooted ideal of successive life course events against the background of financial stability. 
Although in Russian-speaking countries, a different connotation of maturity prevails along with younger maternity, this cultural normative seemed to weaken for half of the highly skilled migrants in the sample. Under restrictive conditions, they had to adjust their behaviours and re-prioritise decisions. This indicates the impact of contextual factors on work-life balance decisions. Although scholars with migration backgrounds, socialised in the FSU, were likely to have imported their cultural ideals and norms to Germany and rely themselves on these values in their agency, they felt forced to make cuts in these culturally rooted scenarios:

Evgeniya (Postdoc, RU): I'm maybe more Western European now. I believe I have to be able to provide a means of subsistence for my children. I don't feel morally ready for that, I'm afraid of losing my health [...] and I don't think I built a sound career yet.

Nina (Postdoc, RU): In France, I would already have had three children and a career. I often observed working mothers with assistants helping them with children. In Germany, the stereotype of bad mother is omnipresent. Wives of scholars, either native or migrant, usually don't work, take care of children and are proud of that [...] For me, inner balance is important, and in Germany it's [having it all - I.G.] not possible.

\section{Conclusion}

This study has addressed differences in cultural understandings of work-life balance in native and migrant scholars in German academia. In order to overcome monocultural observations and running the risk of bias, the research was based on a comparative culturesensitive methodology and focussed on native German scholars and researchers with migration backgrounds from the FSU. Results showed the heterogeneity of the ostensibly uniform status group of junior scholars and how diverse mindsets contribute to varying interpretations and practices of work-life balance. The same working conditions are perceived differently by individuals with diverse cultural backgrounds; a strong implication for further diversity policies and their evaluation. This should be addressed in order to make employment conditions in German academia more attractive for social groups representing different migration and cultural backgrounds.

This study advances the research by not only discussing elements of work-life balance for native and migrant highly skilled scholars, but also by linking individual meanings with practices. Cultural differences were revealed in relation to academic work, family life and expectations of institutional support. All three components formed parts of the work-life balance construct for German- and Russian-speaking individuals, yet varied in their roles and values within the hierarchy of interpretations, mirrored in the resulting individual practices. The meanings in both groups were rooted in traditional cultural notions valid in respective societies, and concurrently, they differed from each other in a subtle way.

Addressing a rare issue within the discourse of highly skilled migration, the study identified striking disparities characterised by family formation notions, enhanced by persistence of negative stereotypes towards mothers (Huopalainen and Satama, 2019). It found highly diversified interpretations and practices related to work-life balance within both studied groups. On the one hand, German scholars had certain ideas regarding the order in which work and family life tasks should be mastered and unconsciously preferred a sequential succession of professional and family events (Bernardi and Keim, 2013). This indicates the continuing influence of a standard employment relationship notion that barely exists in German academia. On the other hand, educational climbers represented alternative gender role models. Russian-speaking researchers regarded parenthood and employment as simultaneous elements, although adjustments were needed. 
Social background represented an additional intersectional category that further diversified junior scholars, particularly professional women prone to conservative gender role models. Surprisingly, alternative work-life balance models, though actively practised by highly skilled scholars, have been rarely institutionalised or communicated openly. This polarisation exists not only on the individual level. Findings demonstrated that organisational structures, initially created to support academic workers, are de facto unable to provide equal opportunities for all. Instead, they stigmatise certain groups of people who do not comply with the widespread notion of the ideal mother and other family-related images.

The insights of the study have strong policy implications. First, at the meso level, universities might introduce regular employee surveys to target individual needs associated with work-life balance. To institutionalise alternative gender role models and reduce negative stereotypes, the practices of parent scholars could be more widely publicised and celebrated. Second, integrating men more strongly into academic diversity policies could create additional benefits on both individual and organisational levels by establishing a parental leave culture and reducing negative stereotypes for mothers. Unlike currently handling, breaking up gender stereotypes and related male academic cultures, as well as sensibilisation towards diverse gender role models should not remain women's business. Further research might address this issue and analyse the ways men interpret work-life balance, how they voice their needs and the extent to which institutions fulfil them.

All in all, work-life balance should be further considered and evaluated from the perspective of cultural diversity and take into account individual needs. Focussing solely on the dominant group in German academia risks a biased understanding and implementation of diversity actions, since without addressing researchers with migration backgrounds, connotations of diversity will be dominated by the exclusively German perspective. Recognising that perceptions and experiences of non-German scholars are vital for increasing attractiveness and gender equality in German research institutions, it is crucial to address the current lack of diversified gender role models in German academia.

\section{References}

Arrigoitia, M.F., Beetham, G., Jones, C.E. and Nzinga-Johnson, S. (2015), "Women's studies and contingency: between exploitation and resistance", Feminist Formations, Vol. 27 No. 3, pp. 81-113.

Beaufaÿs, S. (2013), "Wissenschaftskultur - kein Wandel in Sicht”, in Bundesministerium für Bildung und Forschung (BMBF) (Ed.), Familienfreundlichkeit an deutschen Hochschulen, Schritt für Schritt, Bonn, p. 7 (Hrsg.).

Beham, B., Drobnič, S., Präg, P., Baierl, A. and Eckner, J. (2019), "Part-time work and gender inequality in Europe: a comparative analysis of satisfaction with work-life balance", European Societies, Vol. 21 No. 3, pp. 378-402.

Bernardi, L. and Keim, S. (2013), "Anfang dreißig und noch kinderlos? Lebenswege und Familienmodelle berufstätiger Frauen aus Ost- und Westdeutschland”, in Konietzka, D. and Kreyendeld, M. (Eds), Ein Leben ohne Kinder. Ausmaß, Strukturen und Ursachen von Kinderlosigkeit, Springer VS, Wiesbaden, pp. 173-190.

Bosch, N.V. and Ramos, A.M.G. (2013), "Beyond the work-life balance: family and international mobility of the highly skilled", Sociología y tecnociencia, Vol. 3 No. 3, pp. 55-76.

Briedis, K., Jaksztat, S., Preßler, N., Schürmann, R. and Schwarzer, A. (2014), Berufswunsch Wissenschaft? Laufbahnentscheidungen für oder gegen eine wissenschaftliche Karriere (Forum Hochschule 8), DZHW, Hannover.

Busso, S. and Rivetti, P. (2014), "What's love got to do with it? Precarious academic labour forces and the role of passion in Italian universities", Recherches sociologiques et anthropologiques, Vol. 45 Nos 45-2, pp. 15-37. 
Clarke, C.A. and Knights, D. (2015), "Careering through academia: securing identities or engaging ethical subjectivities?", Human Relations, Vol. 68 No. 12, pp. 1865-1888.

Corbin, J. and Strauss, A. (2008), Techniques and Procedures for Developing Grounded Theory. Basics of Qualitative Research, 3rd ed., Sage, Thousand Oaks, CA.

DAAD (2016), Wissenschaft weltoffen. Daten und Fakten zur Internationalität von Studium und Forschung in Deutschland, Bertelsmann Verlag, Bielefeld.

Dorenkamp, I. and Süß, S. (2017), "Work-life conflict among young academics: antecedents and gender effects", European Journal of Higher Education, Vol. 7 No. 4, pp. 402-423.

Dubois-Shaik, F. and Fusulier, B. (2017), "Understanding gender inequality and the role of the work/ family interface in contemporary academia: an introduction" European Educational Research Journal, Vol. 16 Nos 2-3, pp. 99-105.

European Commission (2016), She Figures 2015, Publications Office of the European Union, Luxembourg.

Federal Statistical Office (2016), Wiesbaden, available at: www.destatis.de

Gassmann, F. (2018), "Wissenschaft als Leidenschaft? Über die Arbeits- und Beschäftigungsbedingungen wissenschaftlicher Mitarbeiter", Campus Verlag, Vol. 15, Frankfurt/New York.

Gewinner, I. (2017), “Conceptualising fertility and migration: the case of Academia”, paper presented at international workshop "Fertility of Migrants and Minorities", Hanover, 6-8 February.

Gewinner, I. (2018), “German early career researchers in gender studies: do networks matter?”, Journal of Applied Social Theory, Vol. 1 No. 2, pp. 58-82.

Gill, R. (2010), "Breaking the silence: the hidden injuries of the Neoliberal University", in Ryan-Flood, R. and Gill, R. (Eds), Secrecy and Silence in the Research Process: Feminist Reflections, Routledge, Abingdon, pp. 228-244.

Glaser, B.G. and Strauss, A.L. (1967), “The constant comparative method of qualitative analysis", The Discovery of Grounded Theory: Strategies for Qualitative Research, Vol. 101 p. 158.

Haas, B., Hartel, M. and Wallice, C. (2004), "Work-care balance? Cross national models for comparing Eastern and Western Europe", Espanet Conference, Denmark, October, pp. 1-3.

Hilevych, Y. (2016), Strong Families and Declining Fertility, Wageningen University, Wageningen.

Huopalainen, A.S. and Satama, S.T. (2019), "Mothers and researchers in the making: negotiating 'new' motherhood within the 'new' academia", Human Relations, Vol. 72, No. 1, pp. 98-121, available at: https://doi.org/10.1177/0018726718764571

Jacob, A.K. (2014), "Diversität unter Wissenschaftler/innen an deutschen Hochschulen”, in Krempkow, R., Pohlenz, Ph. and Huber, N. (Eds), Diversity Management und Diversität in der Wissenschaft, Bielefeld, pp. 249-269.

Konsortium Bundesbericht Wissenschaftlicher Nachwuchs (2017), "Statistische Daten und Forschungsbefunde zu Promovierenden und Promovierten in Deutschland", WBV, Konsortium Bundesbericht Wissenschaftlicher Nachwuchs, Bielefeld.

Krapf, S. and Wolf, K. (2016), "Persisting differences or adaptation to German fertility patterns? First and second birth behavior of the 1.5 and second generation Turkish migrants in Germany", Social Demography Forschung an der Schnittstelle von Soziologie und Demografie, Springer VS, Wiesbaden, pp. 137-164.

Kreckel, R. (2016), "Zur Lage des wissenschaftlichen Nachwuchses an Universitäten: Deutschland im Vergleich mit Frankreich, England, den USA und Österreich”, Beiträge zur Hochschulforschung, Vol. 38 Nos 1-2, pp. 12-40.

Krell, G., Ortlieb, R. and Rainer, A. (2006), "Research note: women's academic careers in business administration and economics: findings of a multi-level survey", Management Revue, Vol. 17 No. 2, pp. 181-183.

Kunadt, S. (2015), Kinderbetreunngsangebote für eine bessere Vereinbarkeit von Wissenschaft und Familie: Ergebnisse einer Evaluationsstudie aus den Jahren 2010/2011, (GESIS Papers, 2015/07), GESIS - Leibniz- Institut für Sozialwissenschaften, Köln, available at: https://doi.org/10.21241/ ssoar.43225 
Leinfellner, S. and Bomert, C. (2017), "Elternschaft und Wissenschaft im Kontext neoliberaler Transformationen: Alte oder neue Dilemmata bei der Vereinbarkeit von Reproduktions- und Erwerbsarbeit?", in Alemann, A.v., Beaufays, S. and Kortendiek, B. (Eds), Alte neue Ungleichheiten? Auflösungen und Neukonfigurationen von Erwerbs- und Familiensphäre, Verlag Barbara Budrich, Opladen, pp. 163-181, available at: https://nbn-resolving.org/urn:nbn:de:0168-ssoar-58511-2

Metz-Göckel, S., Heusgen, K., Möller, C., Schürmann, R. and Selent, P. (2014), Karrierefaktor Kind. Zur generativen Diskriminierung im Hochschulsystem, Budrich, Leverkusen.

Meyer, T. (2006), "Private Lebensformen im Wandel", Die Sozialstruktur Deutschlands, VS Verlag für Sozialwissenschaften, pp. 331-357.

Milewski, N. (2010), "Immigrant fertility in West Germany: is there a socialization effect in transitions to second and third births?", European Journal of Population/Revue européenne de Démographie, Vol. 26, No. 3, pp. 297-323.

Möller, C. (2011a), "Soziale Herkunft von Nachwuchswissenschaftler/innen. Elterliche Bildung und Karrierewege der Kollegiatinnen des Graduiertenkollegs ,Geschlechterverhältnis und sozialer Wandel", Von der Forschung zur Förderung: Promovierende im Blick der Hochschulen. Reihe Bildung-Hochschule-Innovation, Vol. 11, pp. 85-103.

Möller, C. (2011b), “Wissenschaftlicher Mittelbau - privilegiert und prekär?”, Journal Netzwerk Frauenund Geschlechterforschung NRW, Vol. 28, pp. 41-49.

Oechsle, M. and Reimer, T. (2016), "Väter zwischen Beruf und Familie. Handlungskrisen, Bewältigungsstrategien und gesellschaftliche Transformationsprozesse”, Österreichische Zeitschrift für Soziologie, Vol. 41 No. 1, pp. 213-237.

Pfau-Effinger, B. (2004), "Socio-historical paths of the male breadwinner model - an explanation of cross-national differences", The British Journal of Sociology, Vol. 55 No. 3, pp. 377-399.

Powell, K. (2015), "Work-life balance: lab life with kids", Nature, Vol. 517 No. 7534, pp. 401-403.

Rusconi, A. and Solga, H. (2011), "Linked Lives' in der Wissenschaft - Herausforderungen für berufliche Karrieren und Koordinierungsarrangements", in Rusconi, A. and Solga, H. (Eds), Gemeinsam Karriere machen. Die Verflechtung von Berufskarrieren und Familie in Akademikerpartnerschaften, Verlag Barabara Budrich, Opladen/Berlin/Farmington Hills, MI, pp. 11-50.

Salminen-Karlsson, M., Wolffram, A. and Almgren, N. (2018), "Excellence, masculinity and work-life balance in academia: voices from researchers in Germany and Sweden", International Journal of Gender, Science and Technology, Vol. 10 No. 1, pp. 52-71.

Sang, K., Al-Dajani, H. and Özbilgin, M. (2013), "Frayed careers of migrant female professors in British academia: an intersectional perspective", Gender, Work \& Organization, Vol. 20 No. 2, pp. 158-171.

Schürmann, R. and Sembritzki, T. (2017), "Wissenschaft und Familie”, Analysen zur Vereinbarkeit beruflicher und familialer Anforderungen und Wünsche des wissenschaftlichen Nachwuchses, Projektbericht, DZHW, Hannover, 126pp.

Sieverding, M., Eib, C., Neubauer, A.B. and Stahl, T. (2018), "Can lifestyle preferences help explain the persistent gender gap in academia? The 'mothers work less' hypothesis supported for German but not for US early career researchers", PloS One, Vol. 13 No. 8.

Smith, J. and Gardner, D. (2007), "Factors affecting employee use of work-life balance initiatives", New Zealand Journal of Psychology, Vol. 36 No. 1, pp. 3-12.

study.eu (2018), The Study.EU Country Ranking 2018 for International Students, available at: www.study.eu/article/the-study-eu-country-ranking-2018-for-international-students (accessed 25 September 2019).

Toffoletti, K. and Starr, K. (2016), "Women academics and work-life balance: gendered discourses of work and care", Gender, Work \& Organization, Vol. 23 No. 5, pp. 489-504.

Tzanakou, C. (2017), "Dual career couples in academia, international mobility and dual career services in Europe", European Educational Research Journal, Vol. 16 Nos 2-3, pp. 298-312.

Ullrich, P. (2016), "Prekäre Wissensarbeit im akademischen Kapitalismus", Soziologie, Vol. 45 No. 4, pp. 388-411. 
Van Dyk, S. and Reitz, T. (2016), "Projektförmige Polis und akademische Prekarität im universitären Feudalsystem (Teil 2)", Sozblog, available at http://soziologie.de/blog/2016/06/projektfoermigepolis-und-refeudalisierung-teil-2 (accessed 16 August 2019).

Vohlídalová, M. (2014), "Academic mobility in the context of linked lives”, Human Affairs, Vol. 24 No. 1, pp. 89-102.

Wolffram, A. (2015), "Karrierewege promovierter Ingenieur- und Naturwissenschaftlerinnen aus Osteuropa”, Beiträge zur Hochschulforschung, Vol. 7 No. 3, pp. 100-117.

\section{Further reading}

Dörre, K. (2017), "Prekarität", Lexikon der Arbeits-und Industriesoziologie, Nomos Verlagsgesellschaft, Baden-Baden, pp. 258-262.

Glaser, B. and Strauss, A. (1967), The Discovery of Grounded Theory, Adine, Chicago, IL.

Glaser, B.G. and Strauss, A.L. (2008), Grounded Theory: Strategien qualitativer Forschung (Auflage: 1. Nachdr. 2008 der 2., korr. Aufl. 2005.), Hans Huber, Bern.

Masselot, A. (2011), "Highly skilled migrants and transnational care practices: balancing work, life and crisis over large geographical distances", Canterbury Law Review, Vol. 17, Special Issue, pp. 299-316.

Meares, C. (2010), “A fine balance: women, work and skilled migration”, Women's Studies International Forum, Vol. 33 No. 5, pp. 473-481.

Corresponding author

Dr Irina Gewinner can be contacted at: irina.gewinner@uni.lu

For instructions on how to order reprints of this article, please visit our website: 